\title{
Students' Thinking and the Depth of the Mathematics Curriculum
}

\author{
Laura B. Kent ${ }^{1}$ \\ ${ }^{1}$ College of Education and Health Professions, University of Arkansas, Fayetteville, AR, USA \\ Correspondence: Laura B. Kent, College of Education and Health Professions University of Arkansas \\ Fayetteville, AR 72701, USA. E-mail: 1kent@uark.edu
}

Received: October 15, 2014

Accepted: November 4, $2014 \quad$ Online Published: November 10, 2014

doi:10.5539/jel.v3n4p90

URL: http://dx.doi.org/10.5539/jel.v3n4p90

\begin{abstract}
This article explores the impact of students' thinking centered professional development on mathematics teaching and learning. Purposeful pedagogy and problem posing are examined as mechanisms by which teachers can potentially deepen students' understanding of mathematics. A classroom example comparing student generated strategies versus algorithmic approaches also highlights the benefits of instructional approaches that emphasize students' understanding of mathematics.
\end{abstract}

Keywords: mathematics, learning, cognition, professional development

\section{Introduction}

The most prevalent international critique of mathematics education in the United States of America over the last several decades has been the "mile wide inch deep" phrase (National Governors Association, 2010). The TIMSS studies provided stark evidence that typical US classrooms were characterized by coverage of mathematics content in ways that reflected front loading of instruction prior to allowing students opportunities to engage in any kind of authentic mathematical activity (Stigler, Gallimore, \& Hiebert, 2000). Despite several national initiatives to reform mathematics curricula, many teachers have largely maintained a traditional approach consisting of a review of content from previous lessons, presentation of new material, and practice of strategies for doing math from worked examples, either by the teacher or the text materials (Boaler, 2013). The purpose of this article is to describe the potential for authentic change in students' learning experiences through innovative professional development designed to enhance teachers' mathematics instruction.

\section{From NCTM Standards to Common Core}

The NCTM Standards documents proposed a shift to more problem based learning and real-life applications of mathematics in K-12 $(1989,2000)$. The documents were heralded by mathematics educators as a potential solution to what was perceived to be a watering down of the mathematics curriculum. Several factors inhibited the NCTM standards from being implemented with fidelity in most classrooms. One factor was the attempt to adapt the national standards to meet the needs of individual states. Modifications to the individual state standards occurred to meet regional and local needs of schools. Additionally, varying interpretations of the language led to substantial changes to the original standards (Hill, 2001).

Another factor that impacted the implementation of the NCTM Standards was the failure of many textbook writers to incorporate these standards in an authentic manner. Several NSF supported projects developed curriculum materials around the NCTM standards for middle grades including Investigations in Number, Data, and Space (2008), Mathematics in Context: A Connected Curriculum for Grades 5-8 (National Center for Research in Mathematical Sciences Education and Freudenthal Institute, 1997-98) and Connected Mathematics Project (Lappan, Fey, Fitzgerald, Freil, \& Phillips, 1991-1997). These materials were developed from researched based information about learning from contextualized situations and international perspectives on learning mathematics. The nature of these curriculum materials was such that the focus was on open response tasks that allowed for multiple types of strategies and solution paths to the correct answer or in many cases open ended tasks that allowed for multiple answers. One aspect that became apparent with these types of curricula was that the teacher played a central role in the degree to which the materials were implemented with fidelity across classrooms (Tarr, Chavez, Reys, \& Reys, 2006).

Positive impacts on student learning were documented from implementation studies of both of these curricula (Reys, Reys, Lappan, Holliday, \& Wasman, 2003; Romberg \& Shafer, 2002; Taber, 1998). However, in many 
ways, these innovative curricula failed to capture national interest in terms of state and local adoptions. And in cases where they were adopted, many teachers and district leaders supplemented the use of these materials with more traditional text materials, including worksheets and online remediation and review software programs for students to practice on basic skills tasks.

Studies of student performance in classrooms in which problem solving was the primary focus of mathematics lessons showed that students did not become weaker in working with number facts as a result of solving word problems in mathematics class (i.e., Carpenter, Fennema, Peterson, Chiang, \& Loef, 1989). However, teachers still struggled to believe that students would not suffer if number computation problems were deemphasized. Confounding the situation for teachers and students was the mismatch between standardized assessments and the newly designed curriculum materials. In the case of the number facts assessments done with primary grades students, there were not as many issues related to the notation of number fact assessments. However, upper grades mathematics assessments often contained items in which not only a standardized algorithm was expected but the representation was in the form of a standardized recording that further limited students' ability to use a different type of strategy to solve a problem.

One implication of not fully embracing the national standards was that teachers were faced with trying to implement problem posing and/or conceptual lessons and computation lessons. Moreover, the implementation predated some of the more recent work on the frameworks of children's thinking about multi-digit whole number computation and development of fraction concepts and procedures (e.g., Baek, 2005; Empson \& Levi, 2011). This resulted in the implementation of disjointed lessons and curricula that at times were based on the students repeating strategies that the teacher showed them and other lessons in which students were asked to think for themselves and discover mathematical ideas (Shew, 1996).

\section{The Common Core Era}

The newly adapted common core standards for mathematics are providing educators with yet another opportunity to transform mathematics classrooms in ways to promote deeper understandings of mathematics. There are fewer content standards per grade level and assessments linked to these standards will be designed and implemented nationally to lessen the possibility of modification of the national standards by states and local districts. The assessments are likely to reflect long advocated for problem solving and sense making in mathematics (National Governors Association, 2010).

As with previous reform efforts, the common core standards for mathematics are an attempt to shift learning experiences for students from rote memorization to learning mathematics with understanding. Several aspects of the common core standards that are potentially transformative are the eight standards for mathematical practice and the integration of the number and algebra strands in the elementary grades. Students are required to draw on the informal and/or prior knowledge of mathematics to solve the problems. The role of the teacher is to scaffold students' strategies after they have had substantial opportunities to make sense of the ideas in the problem on their own or in collaboration with peer students (NCTM, 2014).

Another important aspect of the common core standards for mathematics is the integration of number concepts with algebraic reasoning in the K-6 standards. This aspect has strong potential to transform the learning environment for students at all grade levels. This component of the content standards incorporates research on student thinking and learning from the last several decades. The focus on linking student strategies for working with computational situations to properties of operations is an important step in validating alternative algorithms that can be generalized for all real numbers. For example, helping teachers recognize the informal use of the distributive property of multiplication over addition in students' strategies for working with multiplication problems may help them shift their focus away from traditional recordings of the standards algorithms for multidigit multiplication if they recognize that students are engaged in the same process using a different recording method.

The content standards also give particular attention to the correct use of the equal sign and other notations in mathematics. Replacing algorithmic looking notations with more algebraic representations such as equations will enhance the integration of number and algebra in the elementary grades (National Governors Association, 2010).

\section{4. "Purposeful" Problem Posing}

Problem posing in the common core era is a mechanism by which teachers can assess student understanding of the content, scaffold their thinking through the introduction of meaningful and mathematically appropriate notations. It has the potential to release teachers and students from the constraints of traditional forms of lessons still prevalent in many mathematics textbooks and deepen their understanding of mathematics. It requires careful 
selection and sequencing of high level mathematical tasks (Boston \& Smith, 2009).

Sustained purposeful problem posing requires teachers to make substantial changes to traditional views of mathematics curricula. They must shift their approach to teaching mathematics from a model of content coverage guided externally (i.e., textbooks and pacing guides) to local decision making based on the students' thinking and potential connections to the big ideas. Most teachers find this task daunting and are unwilling to completely let go of a final product - such as the standard algorithm. Most textbooks, while seemingly with good intentions include more problem solving and application situations, almost always default to a standardized approach that both teachers and students perceive to be the most valid in terms of progressing in mathematics.

One of the most significant changes to problem posing in the common core era compared to prior initiatives is the changing model of mathematics professional development. Sustained professional development over a three or more year period is considered the norm along with more emphasis on connections to student thinking in real time through classroom embedded or lesson study type workshops (e.g. Loucks-Horsley, Love, Stiles, Mundry, \& Hewson, 2003). The potential to transform instruction across all grade levels is being evidenced in districts by the willingness in many cases to not adopt mathematics textbooks or to encourage their use as a supplement to the problem based curriculum.

\section{Systemic Change}

One approach to professional development that shows promise in helping teachers implement the common core standards in the area of mathematics is to align professional development for K-12 teachers around the purpose of providing information or frameworks about students' strategies for solving problems in specific content areas. This type of alignment of professional development allows for both horizontal and vertical alignment of content and empowers teachers to incorporate teaching methods such as purposeful problem posing across multiple grades. Moreover, since it is not a specific curriculum, teachers are able to decide how to use the information with their current curricula and other resources.

Mathematics professional development focused on student thinking has been shown to increase student achievement in problem solving (Carpenter et al., 1989). While these studies were conducted with primary grades students and focused on whole number concepts, there is a growing body of research that suggests that students in the upper elementary and middle grades are capable of solving a variety of problems involving fraction and proportion content without direct instruction of standard algorithms (e.g. Empson, 1999; Lamon, 1993). Professional development focused on students' thinking and modeled after programs such as Cognitively Guided Instruction or CGI (Carpenter, Fennema, Franke, Levi, \& Empson, 1999, Fennema, Carpenter, Franke, Levi, \& Empson, 2000) and Developing Mathematical Ideas or DMI (Schifter \& Bastable, 2008) can be useful in supporting a problem posing environment because the content of the professional development sessions helps teachers make sense of students' novel approaches to solving problems.

Seminar-style sessions emphasized frameworks of students' strategies and learning trajectories in the areas of fractions, proportions, and algebraic reasoning. Classroom embedded sessions provided opportunities for teachers to make sense of student thinking in real time. Most of the teachers found the classroom embedded sessions to be the most helpful in making sense of the content presented in the seminar style workshops. The underlying structure of the purposeful pedagogy model is that the launch of the lesson should enhance teachers' assessment of students' understanding of the content. Posing a situation to students with the goal of determining their thinking about the situation is a major shift for secondary mathematics teachers. It requires a different type of planning and lesson structure. The frameworks of student strategies (e.g. Carpenter et al, 1999; Empson \& Levi, 2011; Lamon, 1993) guide teachers' understanding of the strategies that students generally use to solve the problems but may not include all possible cases of students' responses especially regarding misconceptions and prior procedural interference.

\section{Purposeful Pedagogy}

One of the most transformative aspects of purposeful problem posing is the opportunity to use problem posing as a mechanism to simultaneously assess students at both the formative and summative levels through the purposeful pedagogy model (Teachers Development Group, 2010). The purposeful pedagogy instructional model is a structure by which teachers plan lessons based on students' thinking regardless of the specific mathematics content taught. Consider an example from a sixth grade lesson on operations with decimals. The following problem is posed to students.

You have 4.6 pounds of frog food. If you feed your frog

0.1 pound of frog food a day, how many days will your 


\section{frog food last?}

This division problem, posed in a novel context revealed a range of students' thinking about decimal operations as well as misconceptions related to the long division algorithm. Several students added 0.1 repeatedly until they had exhausted all 4.6 pounds and then counted the 0.1 's they had written on their paper to get the answer of 46 . Other students used multiplication strategies and relationships to determine the answer, such as the relationship of $10 \times 0.1=1$ to solve the problem. The full strategy is shown in Figure 1.

$$
\begin{gathered}
10 \times 0.1=1 \\
10 \times 0.1=1 \\
10 \times 0.1=1 \\
10 \times 0.1=1 \\
6 \times 0.1=6 \\
40 \text { days }+6 \text { days }=46 \text { days }
\end{gathered}
$$

Figure 1. Students' use of multiplication relationships to solve frog food problem

Many students performed a standard algorithm to solve the problem. They set up the long division symbol and carried out the steps shown in Figure 2 to solve the problem.

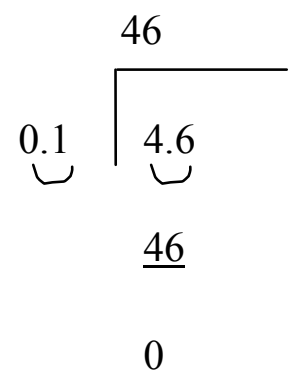

Figure 2. Standard algorithm strategy for solving the frog food problem

The depth of understanding was demonstrated as these students shared their strategies to the rest of the class. The teacher utilized targeted discussion to elicit strategies that would help students clarify and justify their methods for solving the problem (Kazemi \& Hintz, 2014). The student who shared the repeated addition strategy explained, "Every time I used a tenth of a pound of frog food, I knew that that was one day and I counted all of the one tenths and there were 46 of them so I knew that the frog food would last 46 days". The student who used multiplication stated, "I knew that 10 times one tenth is one whole so each pound of frog food would last 10 days, so 4 pounds would last 40 days plus six more days for the six tenths of a pound of frog food would be 46 days". These two strategies were explained using the quantities and the structure of the problem and both students could describe what their answers meant in relation to what was happening in the context.

Contrast the sharing of the strategy in Figure 2 with the previous strategies. When the student shared, he explained, "You can't divide by a decimal so I moved the decimal point over in both numbers. I then divided 46 by one and got 46". The student made no reference to the quantities in the problem and used a mathematical misconception, "can't divide by a decimal", to explain his strategy. Explanations of standard algorithms such as this have potential to hinder students' depth of understanding of number concepts and procedures (Kamii \& Dominick, 1998).

The classroom teacher in this example used the sharing of the student work to both emphasize strategies that were mathematically correct and to establish the norm in her classroom that students should use strategies that they understand and can explain to others. For example, when the student who multiplied ten and one tenth was asked why she chose to multiply by ten, she was able to explain that she wanted a more efficient way to determine the number of days and she knew 10 times one tenth would equal one whole. When the third student was asked why he could not divide by a decimal he said that that was what he was told when dividing by decimals. 


\section{Growth over Time}

Teaching for understanding requires opportunities for students to build connections between their prior and/or intuitive understandings and new ideas (Hiebert \& Carpenter, 1992). Understanding is not easily measured by point in time assessments and usually grows over time and experiences. It requires patience from teachers, coaches, and administrators to thoughtfully examine the types of measures and formats for administration of tests to authentically assess students' understanding. Professional development designed to build up teachers' knowledge of mathematics content through understanding students' thinking and approaches to solving problems is emerging as the cognitive research expands to new areas. A shared goal of teaching for understanding as advocated by the common core standards has the potential to transform students' learning experiences and achievement in mathematics in ways not previously possible.

\section{References}

Baek, J. M. (2005). Children's mathematical understanding and invented strategies for multidigit multiplication. Teaching Children Mathematics, 12(5), 242-247.

Boston, M. D., \& Smith, M. S. (2009). Transforming secondary mathematics teaching: Increasing the cognitive demands of instructional tasks used in teachers' classrooms. Journal for Research in Mathematics Education, 40(2), 119-156.

Carpenter, T. P., Fennema, E., Peterson, P. L., Chiang, C. P., \& Loef, M. (1989). Using knowledge of children's mathematics thinking in classroom teaching: An experimental study. American Educational Research Journal, 26(4), 499-531. http://dx.doi.org/10.3102/00028312026004499

Carpenter, T. P., Fennema, E., Franke, M. L., Levi, L., \& Empson, S. B. (1999). Children's mathematics: Cognitively guided instruction. Portsmouth, NH: Heinemann.

Boaler, J. (2002). Experiencing school mathematics: Traditional and reform approaches to teaching and their impact on student learning. Mahwah, NJ: Lawrence Erlbaum Associates.

Empson, S. B. (1999). Equal sharing and shared meaning: The development of fraction concepts in a first-grade classroom. Cognition and instruction, 17(3), 283-342. http://dx.doi.org/10.1207/S1532690XCI1703_3

Empson, S. B., \& Levi, L. (2011). Extending children's mathematics: Fractions and decimals. Portsmouth, NH: Heinemann.

Fennema, E., Carpenter, T. P., Franke, M. L., Levi, L., \& Empson, S. B. (2000). Children's mathematics: A guide for workshop leaders. Portsmouth, NH: Heinemann.

Hiebert, J., \& Carpenter, T. P. (1992). Learning and teaching with understanding. In D. A. Grouws (Ed.), Handbook of research on mathematics teaching and learning (pp. 65-97). Reston, VA: National Council of Teachers of Mathematics.

Hill, H. (2001). Policy is not enough: Language and interpretation of the standards. American Education Research Journal, 38(2), 289-318. http://dx.doi.org/10.3102/00028312038002289

Kamii, C., \& Dominick, A. (1998). The harmful effects of algorithms in grades 1-4. The teaching and learning of algorithms in school mathematics, 19, 130-140.

Kazemi, E., \& Hintz, A. (2014). Intentional talk: How to structure and lead productive mathematical discussions. Portland, ME: Stenhouse.

Investigations in Number, Data, and Space. (2008). Glenview, IL: Pearson Education.

Lappan, G., Fey, J. T., Fitzgerald, W. M., Freil, S. N., \& Phillips, E. D. (1991-1997). Connected Mathematics Project. White Plains, NY: Dale Seymour Publications.

Lamon, S. J. (1993). Ratio and proportion: Connecting content and children's thinking. Journal for Research in Mathematics Education, 24(1), 41-61. http://dx.doi.org/10.2307/749385

Loucks-Horsley, S., Love, N., Stiles, K. E., Mundry, S., \& Hewson, P. W. (2003). Designing professional development for teachers of science and mathematics. Thousand Oaks, CA: Corwin Press.

National Center for Research in Mathematical Sciences Education and Freudenthal Institute. (1997-1998). Mathematics in context: A connected curriculum for grades 5-8. Chicago: Encyclopedia Britannica Educational Corporation.

National Council of Teachers of Mathematics. (2014). Principles to actions: Ensuring mathematical success for all. Reston, VA: NCTM. 
National Council of Teachers of Mathematics. (2000). Principles and standards for school mathematics. Reston, VA: NCTM.

National Council of Teachers of Mathematics. (1989). Curriculum and evaluation standards. Reston, VA: NCTM.

National Governors Association. (2010). Common core state standards for mathematics. Washington, DC: Council of Chief State School Officers and the National Governors Association Center for Best Practices.

Reys, R., Reys, B., Lappan, G., Holliday, G., \& Wasman, D. (2003). Assessing the impact of standards-based middle grades mathematics curriculum on student achievement. Journal for Research in Mathematics Education, 34(1), 74-95. http://dx.doi.org/10.2307/30034700

Romberg, T, A., \& Shafer, M. (2003). Mathematics in context (MiC): Preliminary evidence about student outcomes. In S. Senk, \& D. Thompson (Eds.), Standards-oriented school Mathematics Curricula: What Are They? What Do Students Learn? (pp. 225-250). Mahwah, NJ: Erlbaum.

Schifter, D., \& Bastable, V. (2008). Developing Mathematical Ideas: A Program for Teacher Learning1. Cases in Mathematics Teacher Education: Tools for Developing Knowledge Needed for Teaching, 35.

Shew, J. A. (1996). Students'beliefs about mathematics and the way it should be learned: A story of struggle and change. University of Wisconsin, Madison.

Stigler, J. W., Gallimore, R., \& Hiebert, J. (2000). Using video surveys to compare classrooms and teaching across cultures: Examples and lessons from the TIMSS video studies. Educational Psychologist, 35(2), 87-100. http://dx.doi.org/10.1207/S15326985EP3502_3

Taber, S. B. (1998). Learning to teach math differently: The effects of the "Investigations" curriculum on teachers' attitudes and practices. Paper presented at the annual meeting of the American Educational Research Association, San Diego, CA.

Tarr, J. E., Chavez, O., Reys, R. E., \& Reys, B. J. (2006). From the written to the enacted curricula: The intermediary role of middle school mathematics teachers in shaping students' opportunity to learn. School Science and Mathematics, 106(4), 191. http://dx.doi.org/10.1111/j.1949-8594.2006.tb18075.x

Teachers Development Group. (2010). Classroom embedded protocol. West Linn, OR.

\section{Copyrights}

Copyright for this article is retained by the author(s), with first publication rights granted to the journal.

This is an open-access article distributed under the terms and conditions of the Creative Commons Attribution license (http://creativecommons.org/licenses/by/3.0/). 